\title{
Community based interventions for the prevention and control of Non-Helmintic NTD
}

\author{
Jai K Das ${ }^{1}$, Rehana A Salam ${ }^{1}$, Ahmed Arshad ${ }^{1}$, Hasina Maredia ${ }^{2}$ and Zulfiqar A Bhutta ${ }^{3,4^{*}}$
}

\begin{abstract}
In this paper, we aim to systematically analyze the effectiveness of community based interventions (CBI) for the prevention and control of non-helminthic diseases including dengue, trypanosomiasis, chagas, leishmaniasis, buruli ulcer, leprosy and trachoma. We systematically reviewed literature published up to May 2013 and included 62 studies in this review.

Findings from our review suggest that CBI including insecticide spraying; insecticide treated bednets and curtains; community education and cleanliness campaigns; chemoprophylaxis through mass drug administration; and treatment have the potential to reduce the incidence and burden of non-helminthic diseases. Lack of data limited the subgroup analysis for integrated and non-integrated delivery strategies however, qualitative synthesis suggest that integrated delivery is more effective when compared to vertical interventions; however, such integration was possible only because of the existing vertical vector control programs.

Community delivered interventions have the potential to achieve wider coverage and sustained community acceptance. Eradicating these diseases will require a multipronged approach including drug administration, health education, vector control and clean water and sanitation facilities. This would require high level governmental commitment along with strong partnerships among major stakeholders.
\end{abstract}

Keywords: NTDs, Non-helminthic, Community based interventions

\section{Introduction}

As discussed in paper 1 of this series [1], non-helminthic infections are a group of viral (dengue fever), protozoal (African trypanosomiasis, chagas and leishmaniasis) and bacterial (buruli ulcer, leprosy and trachoma) diseases endemic amongst the poorest population in the tropical and sub-tropical regions. These infections can lead to burdensome health consequences accountable for severe economic costs including blindness due to trachoma and disfigurement from leishmaniasis, leprosy and buruli ulcer. Some of these neglected tropical diseases (NTD) like African trypanosomiasis, chagas and dengue fever can even become fatal at the later stages of the disease [2]. For a more thorough discussion on the epidemiology and burden of each of these diseases, please refer to Paper 1 of this series [1].

\footnotetext{
* Correspondence: zulfiqar.bhutta@aku.edu

${ }^{3}$ Center of Excellence in Women \& Child Health, The Aga Khan University, Karachi, Pakistan

${ }^{4}$ Center for Global Child Health, Hospital for Sick Children, Toronto, Canada

Full list of author information is available at the end of the article
}

The World Health Organization (WHO) recommends widespread vector control and environmental management to prevent the spread of vector borne diseases including dengue, trypanosomiasis, chagas, leishmaniasis and trachoma. These should be coupled with mass and selective chemotherapy, community participation, active diseases surveillance, health education, capacity building and training of community health workers (CHW), provision of drugs, surgical treatment and rehabilitation for deformities [3]. For trachoma, WHO recommends SAFE strategy for prevention and management of trachoma, which includes lid surgery (S), antibiotics (A), facial cleanliness $(\mathrm{F})$, and environmental improvement (E). In this paper, we aim to systematically analyze the effectiveness of community based interventions (CBI) for the prevention and control of non-helminthic NTD including dengue, trypanosomiasis, chagas, leishmaniasis, buruli ulcer, leprosy and trachoma.

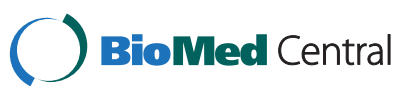

(c) 2014 Das et al.; licensee BioMed Central Ltd. This is an Open Access article distributed under the terms of the Creative Commons Attribution License (http://creativecommons.org/licenses/by/2.0), which permits unrestricted use, distribution, and reproduction in any medium, provided the original work is properly credited. The Creative Commons Public Domain Dedication waiver (http://creativecommons.org/publicdomain/zero/1.0/) applies to the data made available in this article, unless otherwise stated. 
Table 1 Outcomes analyzed

\begin{tabular}{ll}
\hline Diseases & Outcomes analyzed \\
\hline Chagas & Peri-domiciliary Infestation Rate \\
& Domiciliary Infestation Rate \\
& Chagas serology Rate \\
Dengue & Dengue Positive Serostatus \\
& House Index \\
& Mean Bretreau Index \\
& Ovitrap Index \\
Trachoma & Active Trachoma in All Age Groups \\
& Active Trachoma in Children \\
& Chlamydia Trachomatis Infection in All Age Groups \\
& Chlamydia Trachomatis Infection in Children \\
Leishmaniasis & Incidence of Cutaneous Leishmaniasis \\
& Incidence of Visceral Leishmaniasis \\
& Cure Rate for Cutaneous Leishmaniasis \\
Incidence of Leprosy \\
Leprosy
\end{tabular}

\section{Methods}

We systematically reviewed literature published up to May 2013 to identify studies on the effectiveness of CBI for the outlined non-helminthic diseases. Our priority was to select existing randomized, quasi-randomized and before/after studies, in which the intervention was delivered within community settings and the reported outcomes were relevant to the diseases under review. A separate search strategy was developed for each disease using appropriate key words, medical subject heading $(\mathrm{MeSH})$ and free text terms. Search was conducted in the PubMed, Cochrane Libraries, Embase, and WHO Regional Databases. Studies that met the inclusion criteria were selected and double data abstracted on a standardized abstraction sheet. Quality assessment of the included randomized controlled trials (RCT) was done according to the Cochrane risk of bias assessment tool [4]. The outcomes of interest for each of the above diseases are outlined in Table 1. We conducted a meta-analysis for individual studies using the software Review Manager 5.1. Pooled statistics were reported as the relative risk (RR) for categorical variables and standard mean difference (SMD) for continuous variables between the experimental and control groups with $95 \%$ confidence intervals (CI). We also attempted to qualitatively synthesize the findings reported in the included studies for other pragmatic parameters identified in our conceptual framework including intervention coverage, challenges/barriers, enabling factors, aspects related to integrated delivery, monitoring and evaluations and equity. The detailed methodology is described in paper 2 of the series [5].

\section{Review}

We identified 3452 titles from search conducted in all databases. After screening titles and abstracts, 348 full texts were reviewed, of which 62 studies; 21 RCT and 41 before after studies, were included in the review (Figure 1). The characteristics of the included studies are summarized in Table 2. Of these 62 studies, 17 studies were on dengue, 4 on chagas, 12 on leishmaniasis, 6 on leprosy and 23 on trachoma prevention and control. We did not find any quantifiable data from studies on trypanosomiasis and buruli ulcer to be included in the review. For the 21 RCT included in this review; randomization was adequate in all 21 studies, allocation was concealed in 7, adequate sequence generation was done in 10 while studies provided insufficient information on selective reporting which limited us from making any judgment (Table 3).

Included studies mainly focused on community based vector control measures like insecticide spraying and insecticide treated nets (ITN) for dengue, chagas and leishmaniasis; mass drug administration (MDA) for the

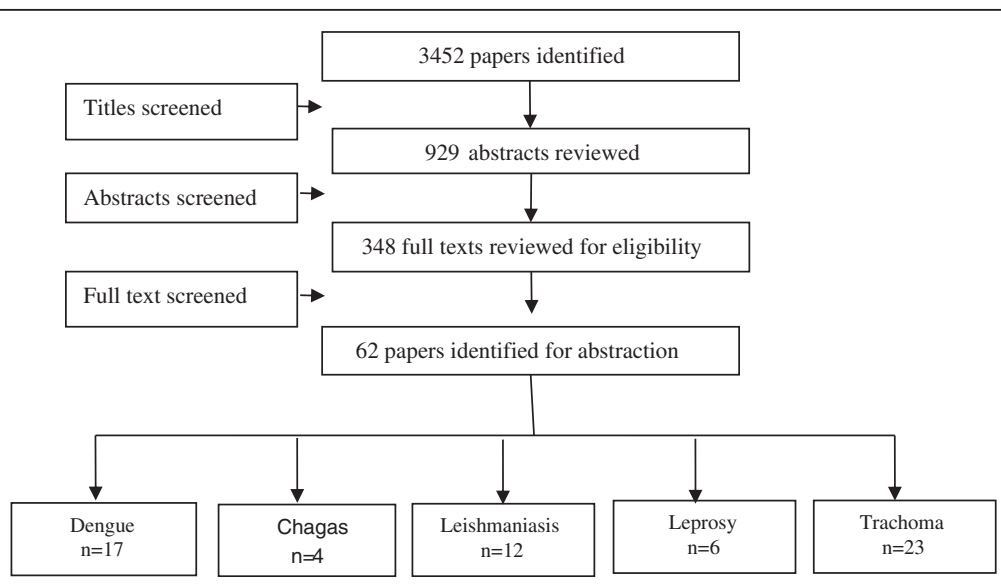

Figure 1 Search flow diagram. 
Table 2 Characteristics of included studies

\begin{tabular}{|c|c|c|c|c|c|}
\hline Study & Study design & Country & Intervention & Target population & $\begin{array}{l}\text { Integrated/ } \\
\text { Non-Integrated }\end{array}$ \\
\hline \multicolumn{6}{|c|}{ Dengue } \\
\hline Gurtler 2009 & Pre-post & Argentina & Preventivelarvicides and insecticide spraying & General population & Non-integrated \\
\hline Seng 2008 & Pre-post & Cambodia & $\begin{array}{l}\text { Preventive guppies reared in household } \\
\text { water tanks }\end{array}$ & General population & Non-integrated \\
\hline Bang 1972 & Pre-post & Thailand & Preventive spraying & General population & Non-integrated \\
\hline Kittayapong 2008 & Pre-post & Thailand & Preventive vector control & General population & Non-integrated \\
\hline Madarieta 1999 & Pre-post & Philippines & Preventive Permethrin treated curtains & General population & Non-integrated \\
\hline Nathan 1982 & Pre-post & West Indies & Preventive insecticide spraying & General population & Non-integrated \\
\hline Neng 1987 & Pre-post & China & $\begin{array}{l}\text { Preventive growing of Chinese cat fish } \\
\text { to consume larvae }\end{array}$ & General population & Non-integrated \\
\hline Pant 1971 & Pre-post & Bangkok & Preventive Malathion aerosols & General population & Non-integrated \\
\hline Pai 2006 & Pre-post & Taiwan & Preventive cleanliness campaign & General population & Non-integrated \\
\hline Nam 1997 & Pre-post & Vietnam & $\begin{array}{l}\text { Preventive community education } \\
\text { and cleanliness campaign }\end{array}$ & General population & Non-integrated \\
\hline Umniyati 2000 & Pre-post & Indonesia & Preventive cleanliness campaign & General population & Non-integrated \\
\hline Uribe 1984 & Pre-post & Columbia & Preventive aerosol applications of Malathion & General population & Non-integrated \\
\hline Winch 2002 & Pre-post & Puerto Rico & $\begin{array}{l}\text { Preventive community education program through } \\
\text { televised public service announcements and posters }\end{array}$ & General population & Non-integrated \\
\hline Kroeger 2006 & $\mathrm{RCT}$ & $\begin{array}{l}\text { Mexico \& } \\
\text { Venezuela }\end{array}$ & Preventive insecticide treated curtains & General population & Non-integrated \\
\hline Vanlerberghe 2009 & $\mathrm{RCT}$ & Cuba & Preventive insecticide treatments of household items & General population & Non-integrated \\
\hline $\begin{array}{l}\text { Espinoza-Gomez } \\
2002\end{array}$ & $\mathrm{RCT}$ & Mexico & Preventive spraying and educational campaign & General population & Non-integrated \\
\hline Lenhart 2008 & $\mathrm{RCT}$ & Haiti & Preventive insecticide treated bed nets & General population & Non-integrated \\
\hline \multicolumn{6}{|c|}{ Chagas } \\
\hline Arias 1999 & Pre-post & Paraguay & $\begin{array}{l}\text { Preventivespraying, housing improvement, and } \\
\text { a combination of spraying plus housing improvement }\end{array}$ & General population & Non-integrated \\
\hline Ferro 1995 & Pre-post & Paraguay & $\begin{array}{l}\text { Preventive insecticide spraying with } \\
\text { lambdacyhalothrin }\end{array}$ & General population & Non-integrated \\
\hline Gurtler 2007 & Pre-post & Argentina & $\begin{array}{l}\text { Preventive community wide spraying } \\
\text { with unspecified insecticide }\end{array}$ & General population & Non-integrated \\
\hline Gurtler 2004 & $\mathrm{RCT}$ & Argentina & Preventiveinsecticide spraying & General population & Non-integrated \\
\hline \multicolumn{6}{|c|}{ Leishmaniasis } \\
\hline Alten 2002 & Pre-post & Turkey & Preventive Deltamethrin impregnated bed nets & General population & Non-integrated \\
\hline Dietze 1997 & Pre-post & Brazil & Affected dogs were eliminated & General population & Non-integrated \\
\hline Jalouk 2007 & Pre-post & Syria & Preventive ITNs vs. non-treated bed nets & General population & Non-integrated \\
\hline $\begin{array}{l}\text { Yaghoobi-Ershadi } \\
2006\end{array}$ & Pre-post & Iran & ITNs, curtains and health education & General population & Non-integrated \\
\hline Mohebali 2010 & Pre-post & Iran & Surveillance followed by treatment of detected cases & Children $<12$ years & $\mathrm{PHC}$ \\
\hline Safi 2012 & Pre-post & Afghanistan & Thermotherapy for Cutaneous Leishmaniasis & General population & Non-integrated \\
\hline $\begin{array}{l}\text { Velasco-Casrejon } \\
1997\end{array}$ & Pre-post & Mexico & Therapeutic localized current radio frequency ablation & General population & Non-integrated \\
\hline Emami 2009 & RCT & Iran & ITNs & General population & Non-integrated \\
\hline Gavgani 2002 & $\mathrm{RCT}$ & Iran & Community wide application of dog collars & Children & Non-integrated \\
\hline Picado 2010 & $\mathrm{RCT}$ & $\begin{array}{l}\text { India and } \\
\text { Nepal }\end{array}$ & ITNs & General population & Non-integrated \\
\hline Reyburn 2000 & RCT & Afghanistan & ITNs and Treated chaddars & General population & Non-integrated \\
\hline Rojas 2006 & RCT & Columbia & Deltamethrin bed nets and health education & General population & Non-integrated \\
\hline
\end{tabular}


Table 2 Characteristics of included studies (Continued)

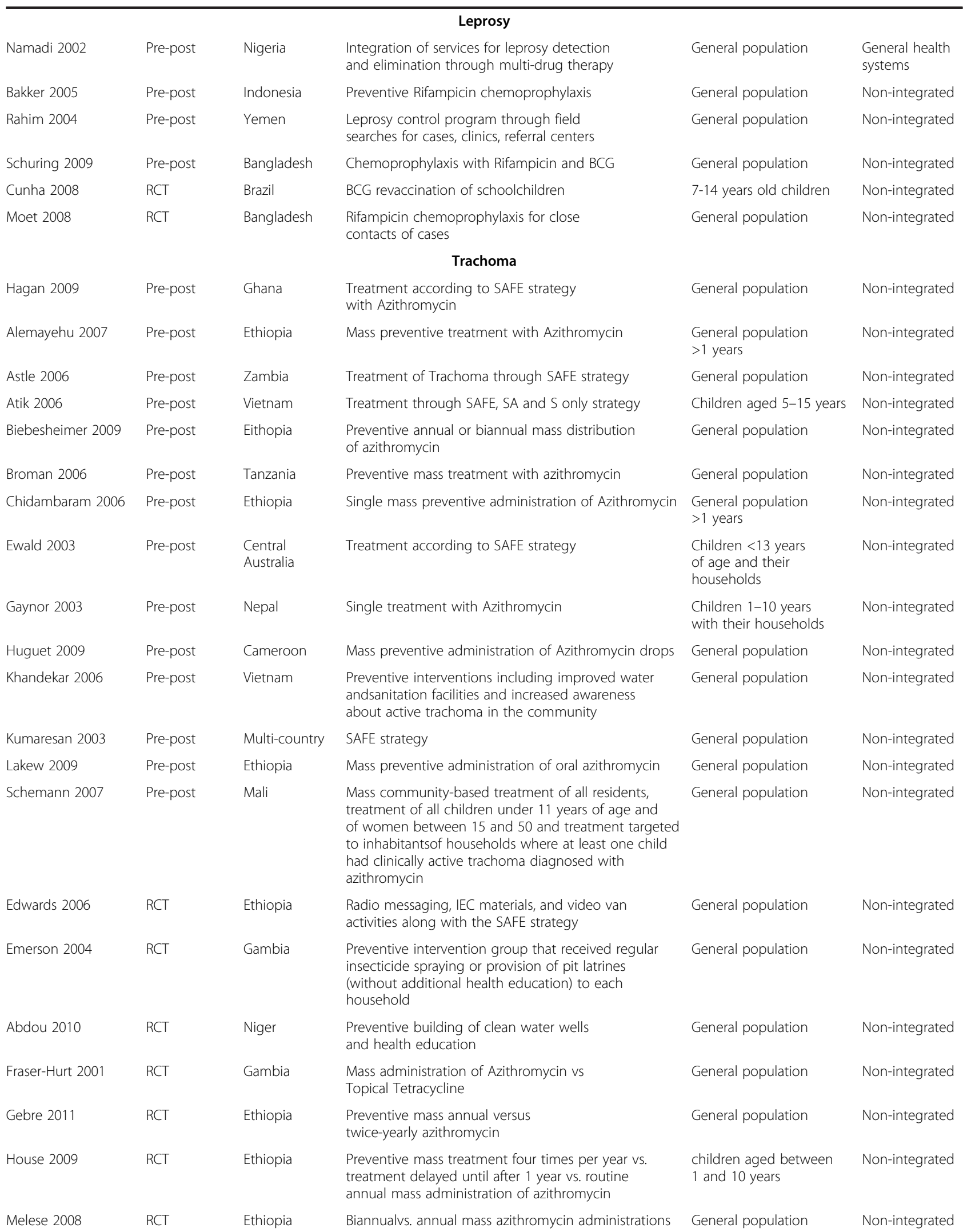


Table 2 Characteristics of included studies (Continued)

\begin{tabular}{|c|c|c|c|c|c|}
\hline Schacter 1999 & $\mathrm{RCT}$ & $\begin{array}{l}\text { Egypt, Gambia } \\
\text { and Tanzania }\end{array}$ & $\begin{array}{l}\text { Community-wide oral azithromycin treatment } \\
\text { or treatment with } 1 \% \text { topicaltetracycline }\end{array}$ & General population & Non-integrated \\
\hline West 2007 & $\mathrm{RCT}$ & Tanzania & $\begin{array}{l}\text { Mass treatment with topical tetracycline } \\
\text { ointmentplus the face-washing programor } \\
\text { treatment only }\end{array}$ & Children 1-7 years & Non-integrated \\
\hline
\end{tabular}

prevention and treatment of leprosy and trachoma and SAFE strategy for trachoma. Two of the studies focused on removing affected dogs and using insecticide treated dog collars for preventing leishmaniasis [6,7]. All the studies for dengue and chagas targeted general population, while two studies for leishmaniasis $[6,8]$, one for leprosy [9] and five from trachoma [10-14] targeted children less than 15 years of age. Delivery mechanism in most of the studies was non-integrated except for two studies $[8,15]$ in which the intervention was integrated with primary health care (PHC). The primary comparison was between the CBI and routine facility based care or no intervention while, we also attempted to conduct subgroup analysis for the relative effectiveness of preventive and therapeutic drug administration and for the evidences from RCT and pre-post studies, where possible, and reported the results accordingly. Due to limited data we could not conduct an integrated versus non-integrated sub-group analysis. The results are summarized in Table 4.

\section{Quantitative synthesis}

CBI for dengue preventive measures including use of ITN and curtains significantly reduced dengue positive serostatus by $70 \%$ (RR: $0.30,95 \%$ CI: $0.23,0.38$ ) while community education alone did not have a significant impact (Figure 2). Preventive community based education and cleanliness campaigns reduced ovitrap index by 25\% (RR: 0.75, 95\% CI: 0.62, 0.91). Insecticide spraying and aerosols significantly reduced house index by $10 \%$ (RR: 0.90, 95\% CI: 0.86, 0.95) while preventive strategies utilizing guppies in water tank and growth of Chinese cat fish to consume larvae also had significant impact on reducing house index. Bednets and curtains had a nonsignificant impact however the studies reported spillover effects and non-suitable controls. Community education alone also did not have any impact.

For chagas disease, CBI including preventive insecticide spraying with housing improvement (ensure smooth, flat, and crack-free walls and ceiling surfaces and improving openings for ventilation and illumination) had a significant impact with a $68 \%$ reduction in domiciliary infestation rate (RR: $0.32,95 \% \mathrm{CI}: 0.19,0.55)$ and a $22 \%$ reduction in serology (RR: $0.78,95 \%$ CI: $0.61,0.98$ ) while it did not show any significant impact on peri-domiciliary infestation rate (Figure 3).
For leishmaniasis, CBI including ITN and curtains with education significantly reduced the incidence of cutaneous leishmaniasis by $58 \%$ (RR: $0.42,95 \%$ CI: 0.36 , 0.49) (Figure 4). Treatment with thermotherapy and radiofrequency resulted in significant 8\% (RR: 0.92, 95\% CI: $0.88,0.96)$ reduction in cure rates of cutaneous leishmaniasis while interventions including surveillance, elimination of dogs, dog collars and ITN had nonsignificant impact on the incidence of visceral leishmaniasis.

For leprosy, treatment with MDA or rifampicin with community education resulted in a $68 \%$ reduction in the incidence of leprosy (RR: 0.32, 95\% CI: 0.30, 0.34) (Figure 5) and $11 \%$ improvement in detection rate (RR: $1.11,95 \% \mathrm{CI}$ : $1.02,1.21)$. One study evaluating the effect of revaccination of school children with BCG showed no impact on the incidence of leprosy.

CBI for trachoma treatment with SAFE strategy and Azithromycin along with community education on hygiene had significant reduction of $76 \%$ (RR: $0.24,95 \%$ CI: $0.21,0.26$ ) (Figure 6) and 33\% (RR: 0.67, 95\% CI: 0.64, 0.69 ) in active trachoma among all age groups and children respectively. Chlamydia trachomatic infections also reduced by $71 \%$ (RR: $0.29,95 \%$ CI: $0.27,0.32$ ) and $79 \%$ (RR: $0.21,95 \%$ CI: $0.18,0.24$ ) among all age groups and children respectively. Subgroup analysis for the relative effectiveness of preventive and therapeutic drug administration and for the evidences from RCT and pre-post studies did not show any major differences.

\section{Qualitative synthesis}

Majority of the studies support that community delivered interventions have the potential to achieve wider coverage and sustained community acceptance [16-19] with the combination approach having a more rapid and sustainable effect compared to individual interventions $[14,16]$. The house-to-house strategy used for the distribution of drugs and commodities also assisted in improving coverage and consequently reducing active disease [14]. Studies also suggest that integrated delivery is more effective when compared to vertical interventions as vertical delivery covers a limited, high-risk population group [16-18]. These integrated programs required strengthened communication and health education components along with broad social participation [17]. However, such integration was reported to be possible only because of the existing vertical vector control programs along with 
Table 3 Quality assessment of the included RCTs

\begin{tabular}{|c|c|c|c|c|c|c|}
\hline Study & Randomization & Sequence generation & $\begin{array}{l}\text { Allocation } \\
\text { concealment }\end{array}$ & $\begin{array}{l}\text { Blinding of } \\
\text { participants }\end{array}$ & $\begin{array}{l}\text { Blinding } \\
\text { of assessors }\end{array}$ & $\begin{array}{l}\text { Selective } \\
\text { reporting }\end{array}$ \\
\hline \multicolumn{7}{|c|}{ Chagas } \\
\hline Gurtler 2004 & Done & Not computerized but done & Not clear & Done & Done & Not clear \\
\hline \multicolumn{7}{|c|}{ Dengue } \\
\hline Kroeger 2006 & Done & Not done & Done & Not done & Not clear & Yes \\
\hline Vanlerberghe 2009 & Done & Not computerized but done & Not clear & Not clear & Not clear & Not clear \\
\hline Espinoza-Gomez 2002 & Done & Not computerized but done & Not clear & Not clear & Not clear & No \\
\hline Lenhart 2008 & Done & Not done & Done & Not clear & Not clear & Not clear \\
\hline \multicolumn{7}{|c|}{ Trachoma } \\
\hline Edwards 2006 & Done & Not clear & Not clear & Not clear & Not clear & Not clear \\
\hline Emerson 2004 & Done & Not clear & Not clear & Not clear & Done & No \\
\hline Abdou 2010 & Done & Not clear & Not clear & Not clear & Not clear & Not clear \\
\hline Fraser-Hurt 2001 & Done & Not clear & Not clear & Not clear & Not clear & Yes \\
\hline Gebre 2011 & Done & Done & Done & Not clear & Done & Not clear \\
\hline House 2009 & Done & Done & Done & Not clear & Done & Not clear \\
\hline Melese 2008 & Done & Done & Done & Not clear & Done & No \\
\hline Schacter 1999 & Done & Done & Not clear & Not clear & Not clear & Yes \\
\hline West 2007 & Done & Not clear & Not clear & Not done & Done & No \\
\hline \multicolumn{7}{|c|}{ Leishmaniasis } \\
\hline Emami 2009 & Done & Done & Not clear & Not clear & Not clear & No \\
\hline Gavgani 2002 & Done & Not done & Not clear & Not clear & Not clear & No \\
\hline Picado 2010 & Done & Not clear & Not clear & Not clear & Not clear & Not clear \\
\hline Reyburn 2000 & Done & Not clear & Not clear & Not clear & Done & No \\
\hline Rojas 2006 & Done & Not clear & Not clear & Not clear & Done & Yes \\
\hline \multicolumn{7}{|c|}{ Leprosy } \\
\hline Cunha 2008 & Done & Done & Done & Not done & Not done & Not clear \\
\hline Moet 2008 & Done & Done & Done & Done & Done & No \\
\hline
\end{tabular}

simultaneous strategic development of the infrastructure for improved water and sanitation $[17,19]$.

One of the major reported enabling factor in community directed programs included intersectoral cooperation involving close coordination between external organization, local municipality and the Ministry of Health $[10,17]$. Another important aspect highlighted in the included studies was the fact that most of the vector control personnel were women from the same community accounting for very low refusals to enter the household premises [17]. To ensure sustainability and preventing future outbreaks, the programs trained a significant number of local human resources along with motivational tools for the continuation of control activities even after the study finished $[17,18]$. Community involvement, knowledge and education were also highlighted as keys components associated with future sustainability as it encourages the community to continue the use of preventive measures $[16,18-20]$. It has been reported that conducting an educational campaign is an effective control measure compared to insecticide spraying because in the absence of education, sustainability cannot be ensured. School education has also been found to be an effective strategy $[20,21]$ as school children communicate with their parents about infection prevention measures and increase parental involvement in infection control., More specific messages about the change in behavior and environment need to be directed towards parents [20]. Involvement of children is postulated to promote behavior change in parents, as well as to introduce the children to the concepts of infection prevention at an early age [20]. Mass media and community-wide events should provide appropriate cues to practice specific behaviors on a routine basis and not just during epidemics, while constant positive feedback should be provided to those who are performing the target behaviors [20]. Community delivered programs could turn out to be more cost effective if all vector control tools were locally produced using locally available 
Table 4 Results for overall and sub-group analysis according to type of study and treatment

\begin{tabular}{|c|c|c|c|c|c|}
\hline \multirow[t]{2}{*}{ Outcomes } & \multicolumn{4}{|c|}{ Estimates $(95 \% \mathrm{Cl})$} & \multirow[b]{2}{*}{ Therapeutic } \\
\hline & Combined & RCTs & Pre-post studies & Preventive & \\
\hline \multicolumn{6}{|c|}{ Chagas } \\
\hline \multirow[t]{2}{*}{ Peri-domiciliary Infestation Rate } & $0.77[0.53,1.14]$ & $0.94[0.67,1.32]$ & $0.17[0.06,0.48]$ & $0.77[0.53,1.14]$ & No studies \\
\hline & 8 datasets, 3 studies & 4 datasets, 1 study & 4 datasets, 2 studies & 8 datasets, 3 studies & \\
\hline \multirow[t]{2}{*}{ Domiciliary Infestation Rate } & $0.32[0.19,0.55]$ & No studies & $0.32[0.19,0.55]$ & $0.32[0.19,0.55]$ & No studies \\
\hline & 4 datasets, 2 studies & & 4 datasets, 2 studies & 4 datasets, 2 studies & \\
\hline \multirow[t]{2}{*}{ Chagas Serology Rate (RR) } & $0.78[0.61,0.98]$ & No studies & $0.78[0.61,0.98]$ & $0.78[0.61,0.98]$ & No studies \\
\hline & 4 datasets, 2 studies & & 4 datasets, 2 studies & 4 datasets, 2 studies & \\
\hline \multicolumn{6}{|c|}{ Dengue } \\
\hline \multirow[t]{2}{*}{ House Index } & $0.84[0.81,0.88]$ & No studies & $0.84[0.81,0.88]$ & $0.84[0.81,0.88]$ & No studies \\
\hline & 9 datasets, 9 studies & & 9 datasets, 9 studies & 9 datasets, 9 studies & \\
\hline \multirow[t]{2}{*}{ Ovitrap Index } & $0.77[0.64,0.92]$ & No studies & $0.77[0.64,0.92]$ & $0.77[0.64,0.92]$ & No studies \\
\hline & 5 datasets, 3 studies & & 5 datasets, 3 studies & 5 datasets, 3 studies & \\
\hline \multirow[t]{2}{*}{ Mean Bretreau Index (SMD) } & $-0.04[-0.28,0.19]$ & $-0.04[-0.28,0.19]$ & No studies & $-0.04[-0.28,0.19]$ & No studies \\
\hline & 5 datasets, 2 studies & 5 datasets, 2 studies & & 5 datasets, 2 studies & \\
\hline \multirow[t]{2}{*}{ Dengue Positive Serostatus } & $0.31[0.18,0.53]$ & $0.33[0.18,0.60]$ & $0.14[0.01,1.62]$ & $0.31[0.18,0.53]$ & No studies \\
\hline & 4 datasets, 4 studies & 2 datasets, 2 studies & 2 datasets, 2 studies & 4 datasets, 4 studies & \\
\hline \multicolumn{6}{|c|}{ Trachoma } \\
\hline \multirow[t]{2}{*}{ Active Trachoma All Age Groups } & $0.24[0.21,0.26]$ & $0.72[0.59,0.88]$ & $0.15[0.14,0.17]$ & $0.72[0.59,0.88]$ & $0.15[0.14,0.17]$ \\
\hline & 6 datasets, 3 studies & 2 datasets, 1 study & 4 datasets, 2 studies & 2 datasets, 1 study & 4 datasets, 2 studies \\
\hline \multirow[t]{2}{*}{ Active Trachoma in Children } & $0.67[0.64,0.69]$ & $0.86[0.83,0.90]$ & $0.38[0.36,0.40]$ & $0.77[0.74,0.79]$ & $0.32[0.29,0.35]$ \\
\hline & 20 datasets, 14 studies & 6 datasets, 4 studies & 14 datasets, 9 studies & 13 datasets, 8 studies & 7 datasets, 6 studies \\
\hline \multirow{2}{*}{$\begin{array}{l}\text { Chlamydia Trachomatic } \\
\text { infection- All Age Groups }\end{array}$} & $0.29[0.27,0.32]$ & $0.28[0.25,0.31]$ & $0.32[0.27,0.37]$ & $0.28[0.25,0.31]$ & $0.36[0.29,0.46]$ \\
\hline & 10 datasets, 6 studies & 5 datasets, 3 studies & 5 datasets, 3 studies & 7 datasets from 5 studies & 3 datasets, 1 studies \\
\hline \multirow{2}{*}{$\begin{array}{l}\text { Chlamydia Trachomatic } \\
\text { infection in Children }\end{array}$} & $0.21[0.18,0.24]$ & $0.15[0.13,0.19]$ & $0.42[0.31,0.55]$ & $0.21[0.18,0.24]$ & No studies \\
\hline & 9 datasets, 7 studies & 6 datasets, 4 studies & 3 datasets, 3 studies & 9 datasets, 7 studies & \\
\hline \multicolumn{6}{|c|}{ Leishmaniasis } \\
\hline \multirow[t]{2}{*}{ Incidence Cutaneous Leishmaniasis } & $0.42[0.36,0.49]$ & $0.40[0.32,0.51]$ & $0.43[0.35,0.53]$ & $0.42[0.36,0.49]$ & No studies \\
\hline & 9 datasets, 5 studies & 5 datasets, 3 studies & 4 datasets, 2 studies & 9 datasets, 5 studies & \\
\hline \multirow[t]{2}{*}{ Incidence of Visceral Leishmaniasis } & $0.93[0.83,1.04]$ & $0.97[0.84,1.12]$ & $0.87[0.73,1.04]$ & $0.93[0.83,1.04]$ & No studies \\
\hline & 4 datasets, 4 studies & 2 datasets, 2 studies & 2 datasets, 2 studies & 4 datasets, 4 studies & \\
\hline \multirow{2}{*}{$\begin{array}{l}\text { Cure Rate for Cutaneous } \\
\text { Leishmaniasis (RR) }\end{array}$} & $0.92[0.88,0.96]$ & No studies & $0.92[0.88,0.96]$ & No studies & $0.92[0.88,0.96]$ \\
\hline & 2 datasets, 2 studies & & 2 datasets, 2 studies & & 2 datasets, 2 studies \\
\hline \multicolumn{6}{|c|}{ Leprosy } \\
\hline \multirow[t]{2}{*}{ Leprosy Incidence } & $0.32[0.30,0.34]$ & $0.67[0.49,0.92]$ & $0.31[0.29,0.33]$ & $0.32[0.30,0.34]$ & No studies \\
\hline & 8 datasets, 5 studies & 1 datasets, 1 studies & 7 datasets, 4 studies & 8 datasets, 5 studies & \\
\hline \multirow[t]{2}{*}{ Leprosy detection rate } & $1.11[1.02,1.21]$ & No studies & $1.11[1.02,1.21]$ & $1.11[1.02,1.21]$ & No studies \\
\hline & 2 datasets, 2 studies & & 2 datasets, 2 studies & 2 datasets, 2 studies & \\
\hline
\end{tabular}

Estimates in bold represents statistical significance.

materials [16]. The low cost and simplicity of impregnated bed nets and curtains ensures their sustainable use in rural communities, given that local people recognize the dangers of vectors, and are amenable to the use of these commodities [22]. Some broader influencing factors included favorable political and sociocultural context that supports discussion of issues affecting health and wellbeing of individuals and community, acquisition of knowledge, and active community involvement in implementation of the program [19].

A few of the barriers reported to hinder effective program implementation and coverage included incomplete surveillance coverage, climatic conditions favorable to the vectors and lack of adequate and sustained community 


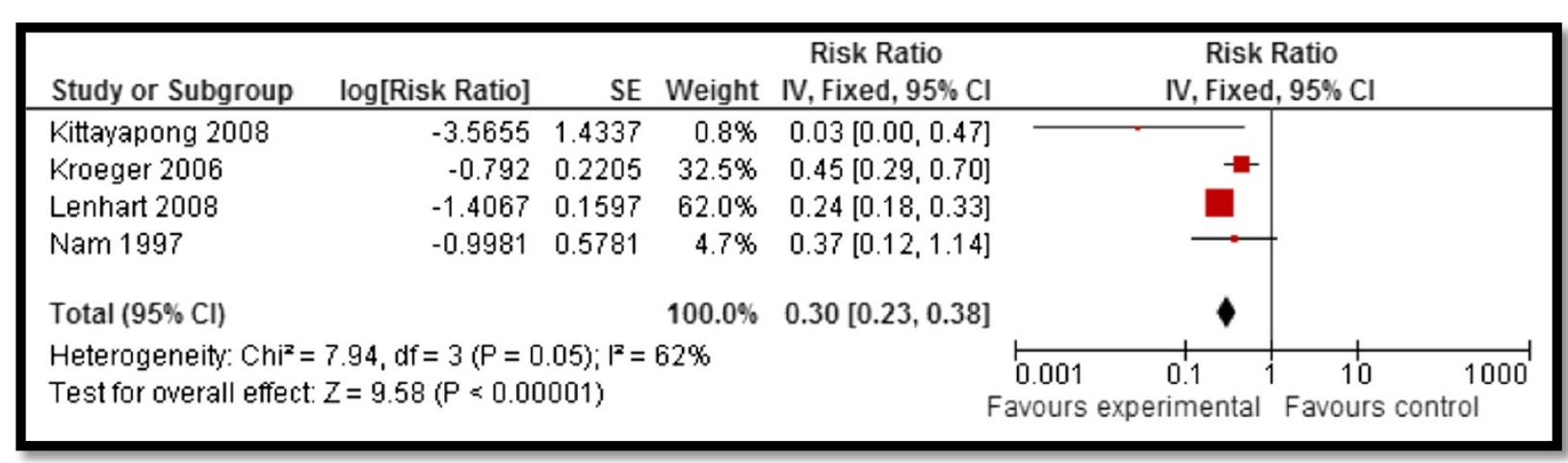

Figure 2 Forest plot for the impact of $\mathrm{CBI}$ on dengue seropositive status.

participation [17]. House-to-house larval surveys are typically plagued by difficulties of access, issues of acceptability, coverage and delivery, which frequently compromise the effectiveness of the available vector control tools [17]. For sustainability, surveillance for reintroduction of infectious diseases is necessary to ensure complete eradication $[23,24]$. There is lack of new, more effective insecticide products that last longer along with the water coverage and storage issues [17]. Certain components of infection control programs require a change in the behaviors of all those at risk as well as the provision of clean water and sanitation. This area has been particularly challenging as change in behavior is slow and provision of water and latrines involves several other sectors and may be costly in resource limiting settings [14]. Maintenance of the hardware and certain health behaviors are also needed to derive health benefits from new housing initiatives [12]. Another important barrier to successful program implementation is the identification of neighborhoods at increased risk of infestation and transmission for developing

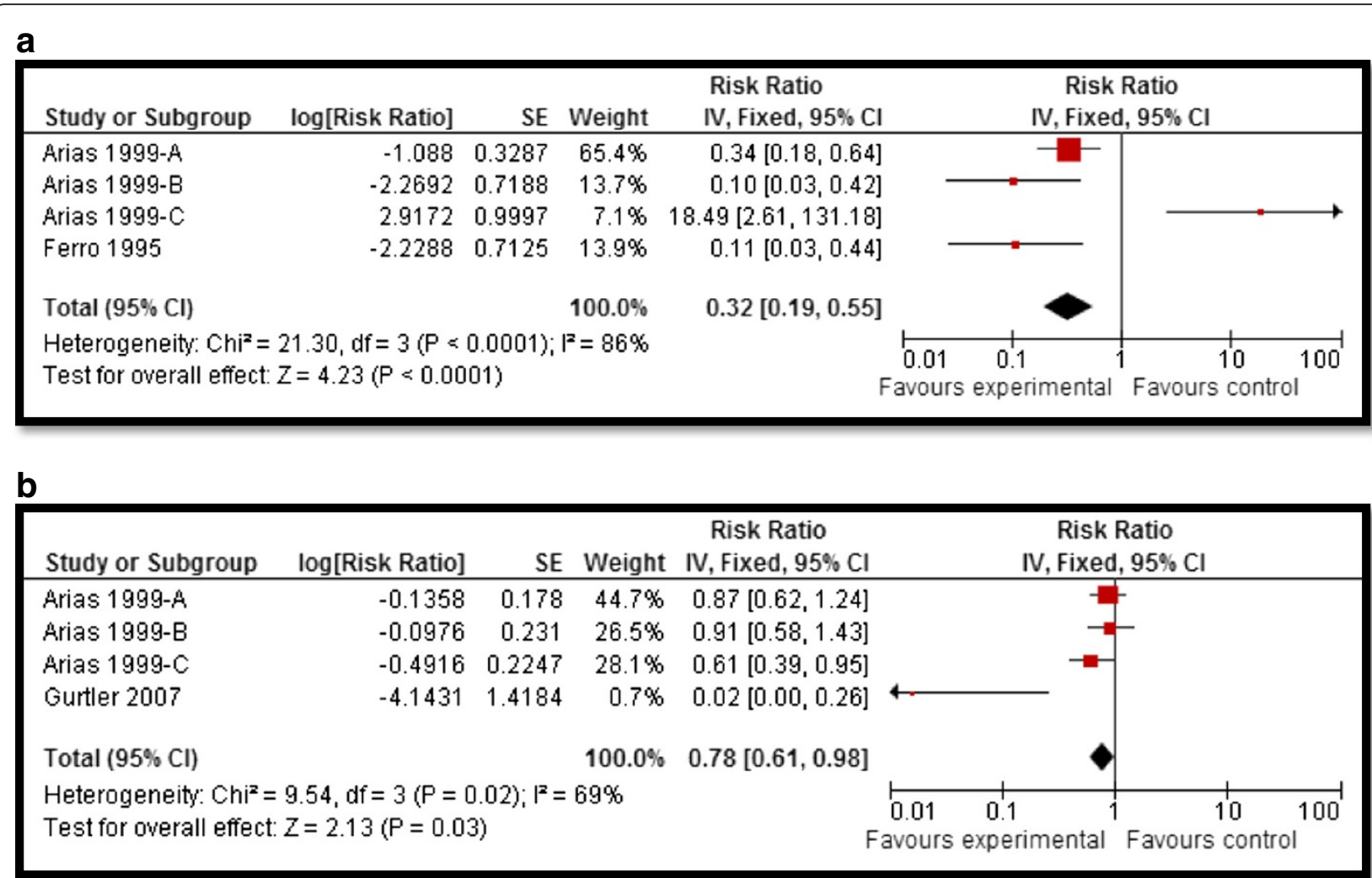

Figure 3 Forest plot for the impact of $\mathrm{CBI}$ on chagas domiciliairy infestation rate and serology. $\mathbf{a}$ and $\mathbf{b}$. 


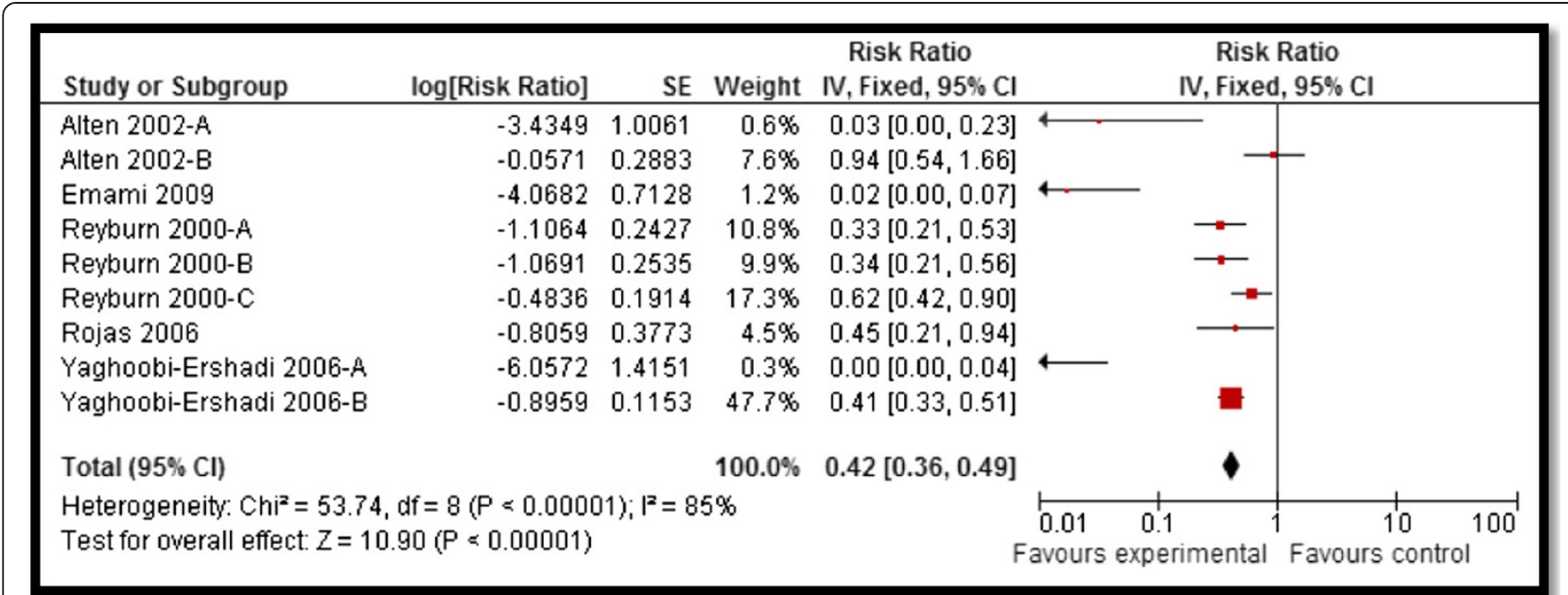

Figure 4 Forest plot for the impact of $\mathrm{CBI}$ on incidence of cutaneous leishmaniasis.

more cost-effective, targeted control strategies [17]. Effective surveillance coverage of closed or vacant houses also remains to be addressed $[18,25]$.

\section{Discussion}

Findings from our review suggest that CBI including insecticide spraying; ITN and curtains; community education and cleanliness campaigns; chemoprophylaxis through MDA; and treatment have the potential to reduce the incidence and burden of non-helminthic NTDs. Figure 7 depicts the summary of evidence suggesting areas of benefit by disease. A range of CBI are effective in reducing positive serostatus, house index and ovitrap index for dengue, domiciliary infestation rates and serology for chagas, incidence and cure rates of cutaneous leishmaniasis, incidence and detection of leprosy, active trachoma and chlamydia trachomatic infections. Although some studies did not report significant impacts on Breteau index and peridomiciliary infestation rates but both indices have limitations when used to assess the quantitative impact of control interventions, partly because they are based on presence/absence of immature stages of the larval cycle and it is often difficult to show significant intervention effects on larval indices [17].

Lack of data limited the subgroup analysis for integrated and non-integrated delivery strategies however, qualitative synthesis suggest that community delivered interventions with a combination approach have the potential to achieve wider coverage and sustained community acceptance. It also suggests that integrated delivery is more effective when compared to vertical interventions; however such integration requires pre-existing vertical vector control programs. We did not find any quantifiable data for buruli ulcer and African trypanosomiasis. These two diseases

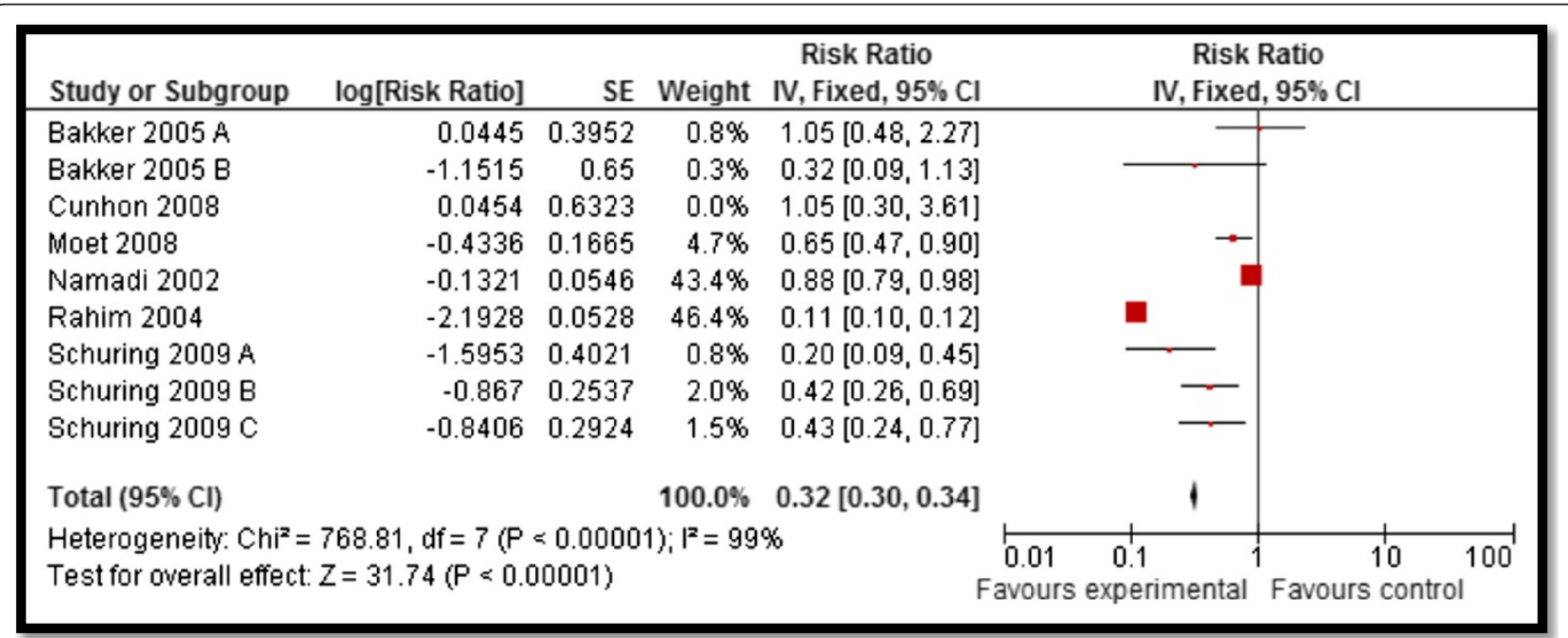

Figure 5 Forest plot for the impact of $\mathrm{CBI}$ on incidence of leprosy. 


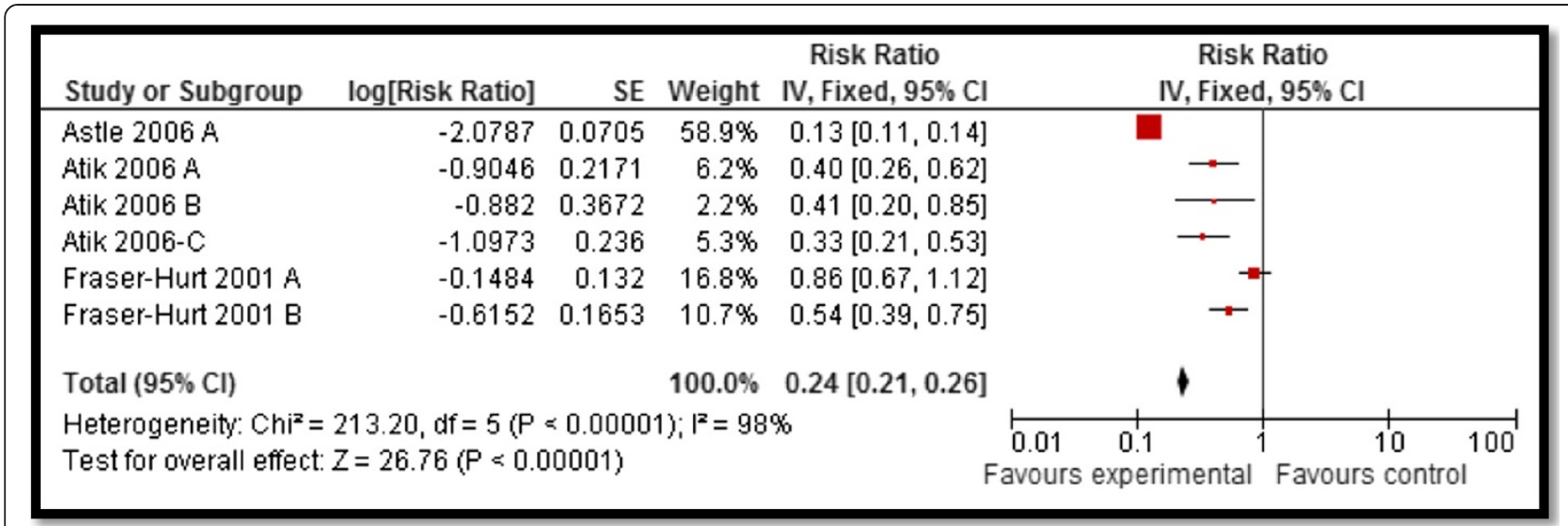

Figure 6 Forest plot for the impact of CBI on active trachoma (all ages).

continue to pose great economic burden as the treatment costs for buruli ulcer often exceed per capita government spending on health [26]. Similarly for human African trypanosomiasis, approximately 300,000 cases are reported globally, with approximately 48,000 resulting deaths annually [27].

In January 2012, WHO published a roadmap setting targets for the prevention, control, elimination and eradication of all the NTDs; setting 6 targets for the elimination of 5 NTDs by 2015, and a further 10 targets by 2020 , either globally or in selected geographical areas, for 9 NTDs. Since then progress has been made to increase coverage for the MDA. Essential preventive and control measures including community-based early detection, health education and MDA can be achieved through CHW training and capacity building [3]. These programs have been successful in increasing coverage by reaching larger populations without access to healthcare.

\begin{tabular}{|c|c|c|c|c|}
\hline Outcomes & Insecticide spraying & $\begin{array}{l}\text { Insecticide treated } \\
\text { bednets and curtains }\end{array}$ & $\begin{array}{l}\text { Community } \\
\text { education and } \\
\text { cleanliness } \\
\text { campaigns }\end{array}$ & $\begin{array}{c}\text { Treatment/ } \\
\text { chemoprophylaxis }\end{array}$ \\
\hline \multicolumn{5}{|c|}{ Dengue } \\
\hline \multicolumn{5}{|l|}{ Positive serostatus } \\
\hline \multicolumn{5}{|l|}{ Ovitrap Index } \\
\hline \multicolumn{5}{|l|}{ House Index } \\
\hline \multicolumn{5}{|c|}{ Chagas } \\
\hline \multicolumn{5}{|l|}{ Perdomiciliairy Infestation rate } \\
\hline \multicolumn{5}{|l|}{ Domiciliary infestation rate } \\
\hline \multicolumn{5}{|l|}{ Serology rate } \\
\hline \multicolumn{5}{|c|}{ Leishmaniasis } \\
\hline \multicolumn{5}{|l|}{ Cutaneous leishmaniasis } \\
\hline \multicolumn{5}{|l|}{ Visceral leishmaniasis } \\
\hline \multicolumn{5}{|l|}{ Cutaneous cure rate } \\
\hline \multicolumn{5}{|c|}{ Leprosy } \\
\hline \multicolumn{5}{|l|}{ Leprosy Incidence } \\
\hline \multicolumn{5}{|l|}{ Leprosy detection rate } \\
\hline \multicolumn{5}{|c|}{ Trachoma } \\
\hline \multicolumn{5}{|l|}{ Active Trachoma (all ages) } \\
\hline \multicolumn{5}{|l|}{ Active Trachoma (children) } \\
\hline \multicolumn{5}{|l|}{ Chlamydia Trachomatic infection (all ages) } \\
\hline Chlamydia Trachomatic infection (children) & & & & \\
\hline
\end{tabular}

Evidence suggests benefit
Inconclusive evidence /no benefit
No evidence

Figure 7 Summary of evidence suggesting areas of benefit according to disease. 
An example is the control of African trypanosomiasis through active community screening coupled with passive screening at health-care facilities for infections. Much has been done since 2010, however still only 37\% of the population in need is being provided with the desired treatment annually while 399 million school age children still in need of treatment [28,29]. This calls for increased scale up of the mass drug campaigns utilizing community platforms to increase coverage. Although CBI are effective in reducing disease burden and improving coverage, there is a major gap in evidence for the effectiveness of integrated community delivered interventions. The major challenges faced include conflict, population growth, vector control, resistance to pesticides and medicines, lack of scale up capacity, lack of research and climate change.

\section{Conclusion}

Eradicating NTDs will require a multipronged approach and our review findings suggest that a range of CBI including drug administration, health education, cleanliness campaigns, vector control and clean water and sanitation facilities have the potential to prevent and control this set of diseases. This would require efforts to overcome the barriers to sustainable implementation including improved surveillance, access and coverage. High level governmental commitment along with strong partnerships among major stakeholders with continuous support by the WHO, United Nations Children's Fund, World Food Programme and the World Bank, relevant national and international non-governmental organizations and key donors to mobilize resources. A major component of CBI should always be the community itself as success of existing NTD programs depends on community structures, customs, beliefs and values that keep community health worker proud and motivated.

\begin{abstract}
Abbreviations
CBI: Community based interventions; CHW: Community health workers; HAT: Human African trypanosomiasis; IDoP: Infectious Diseases of Poverty; ITN: Insecticide Treated Nets; MDA: Mass drug administration; MeSH: Medical subject heading; NTD: Neglected tropical diseases; PHC: Primary health care; RCT: Randomized Controlled Trials; WHO: World health organization.
\end{abstract}

\section{Competing interests}

The authors declare that they have no competing interests.

\section{Authors' contributions}

$Z A B$ was responsible for designing and coordinating the review. AA and $\mathrm{HM}$ were responsible for: data collection, screening the search results, screening retrieved papers against inclusion criteria, appraising quality of papers and abstracting data. RAS and JKD were responsible for data interpretation and writing the review. ZAB critically reviewed and modified the manuscript. All authors read and approved the final manuscript.

\section{Acknowledgements}

The collection of scoping reviews in this special issue of Infectious Diseases of Poverty was commissioned by the UNICEF/UNDP/World Bank/WHO Special Programme for Research and Training in Tropical Diseases (TDR) in the context of a Contribution Agreement with the European Union for
"Promoting research for improved community access to health interventions in Africa".

\section{Author details}

'Division of Women \& Child Health, The Aga Khan University, Karachi, Pakistan. ${ }^{2}$ Brown University, Providence, RI, USA. ${ }^{3}$ Center of Excellence in Women \& Child Health, The Aga Khan University, Karachi, Pakistan. ${ }^{4}$ Center for Global Child Health, Hospital for Sick Children, Toronto, Canada.

Received: 5 January 2014 Accepted: 23 June 2014

Published: 31 July 2014

\section{References}

1. Bhutta ZA, Sommerfeld J, Lassi ZS, Salam RA, Das JK: Global Burden, Distribution and Interventions for the Infectious Diseases of Poverty. Infect Dise of Pov 2014, 3:21.

2. Zhang Y: Helen Keller International Position Paper Control of Neglected Tropical Diseases. New York: Helen Keller International; 2010

3. World Health Organization. Dept. of Control of Neglected Tropical D, Crompton DWT, Daumerie D, Peters P, Savioli L: Working to Overcome the Global Impact of Neglected Tropical Diseases: First Who Report On Neglected Tropical Diseases. Geneva, Switzerland: World Health Organization; 2010.

4. Cochrane Handbook for Systematic Reviews of Interventions Version 5.1.0. [updated March 2011]. In The Cochrane Collaboration. Edited by H JPT, G S. 2011

5. Lassi ZS, Salam RA, Das JK, Bhutta ZA: Conceptual framework and assessment methodology for the systematic review on community based interventions for the prevention and control of IDoP. Infect Dise of Pov 2014, 3:22

6. Gavgani AS, Hodjati MH, Mohite H, Davies CR: Effect of insecticideimpregnated dog collars on incidence of zoonotic visceral leishmaniasis in Iranian children: a matchedcluster randomised trial. Lancet 2002, 360(9330):374-379.

7. Dietze R, Barros GB, Teixeira L, Harris J, Michelson K, Falqueto A, Corey R: Effect of eliminating seropositive canines on the transmission of visceral leishmaniasis in Brazil. Clin Infect Dis 1997, 25(5):1240-1242.

8. Mohebali M, Edrissian GH, Shirzadi MR, Hosseingholizadeh G, Pashaei MH, Ganji A, Zarei Z, Kousha A, Akhoundi B, Hajjaran H: Integrated visceral leishmaniasis surveillance system in primary care for children in Meshkin-Shahr district, north-western Islamic Republic of Iran. East Mediterr Health J 2010, 16(10):1050.

9. Cunha ML, Piovesan-Alves F, Pang LW: Community-based program for malaria case management in the Brazilian Amazon. Am J Trop Med Hyg 2001, 65(6):872-876.

10. Astle WF, Wiafe B, Ingram AD, Mwanga M, Glassco CB: Trachoma control in Southern Zambia-an international team project employing the SAFE strategy. Ophthalmic Epidemiol 2006, 13(4):227-236.

11. Atik B, Thanh TTK, Luong VQ, Lagree S, Dean D: Impact of annual targeted treatment on infectious trachoma and susceptibility to reinfection. JAMA 2006, 296(12):1488-1497.

12. Ewald DP, Hall GV, Franks CC: An evaluation of a SAFE-style trachoma control program in Central Australia. Med J Aust 2003, 178(2):65-68.

13. Gaynor BD, Holbrook KA, Whitcher JP, Holm SO, Jha HC, Chaudhary JSP, Bhatta RC, Lietman T: Community treatment with azithromycin for trachoma is not associated with antibiotic resistance in Streptococcus pneumoniae at 1 year. Br J Ophthalmol 2003, 87(2):147-148.

14. Hagan $M$, Yayemain D, Ahorsu F, Aboe A: Prevalence of active trachoma two years after control activities. Ghana Med J 2009, 43(2):54-60

15. Namadi A, Visschedijk J, Samson K: The leprosy elimination campaign in Jigawa, Nigeria: an opportunity for integration. Lepr Rev 2002, 73(2):138-146

16. Kittayapong P, Yoksan S, Chansang U, Chansang C, Bhumiratana A Suppression of dengue transmission by application of integrated vector control strategies at sero-positive GIS-based foci. Am J Trop Med Hyg 2008, 78(1):70-76.

17. Gurtler RE, Garelli FM, Coto HD: Effects of a five-year citywide intervention program to control Aedes aegypti and prevent dengue outbreaks in northern Argentina. PLoS Negl Trop Dis 2009, 3(4):e427.

18. Seng CM, Setha T, Nealon J, Socheat D, Chantha N, Nathan MB: Community-based use of the larvivorous fish Poecilia reticulata to 
control the dengue vector Aedes aegypti in domestic water storage containers in rural Cambodia. J Vector Ecol 2008, 33(1):139-144.

19. Vanlerberghe V, Toledo ME, Rodriguez M, Gomez D, Baly A, Benitez JR, Van Der Stuyft P: Community involvement in dengue vector control: cluster randomised trial. BMJ 2009, 338:b1959.

20. Winch PJ, Leontsini E, Rigau-Parez JG, Ruiz-Parez M, Clark GG, Gubler DJ: Community-based dengue prevention programs in Puerto Rico: impact on knowledge, behavior, and residential mosquito infestation. Am J Trop Med Hyg 2002, 67(4):363-370.

21. Pai HH, Hong YJ, Hsu EL: Impact of a short-term community-based cleanliness campaign on the sources of dengue vectors: an entomological and human behavior study. J Environ Health 2006, 68(6):35.

22. Yaghoobi-Ershadi MR, Moosa-Kazemi SH, Zahraei-Ramazani AR, Jalai-Zand $A R$, Akhavan AA, Arandian MH, Abdoli H, Houshmand B, Nadim A, Hosseini M: Evaluation of deltamethrin-impregnated bed nets and curtains for control of zoonotic cutaneous leish-maniasis in. Bull Soc Pathol Exot 2006, 99(1):43-48.

23. Broman AT, Shum K, Munoz B, Duncan DD, West SK: Spatial clustering of ocular chlamydial infection over time following treatment, among households in a village in Tanzania. Invest Ophthalmol Vis Sci 2006, 47(1):99-104.

24. Biebesheimer JB, House J, Hong KC, Lakew T, Alemayehu W, Zhou Z, Moncada J, RogÃ@r A, Keenan J, Gaynor BD: Complete local elimination of infectious trachoma from severely affected communities after six biannual mass azithromycin distributions. Ophthalmology 2009, 116(11):2047-2050.

25. Lenhart A, Orelus N, Maskill R, Alexander N, Streit T, McCall PJ: Insecticide treated bednets to control dengue vectors: preliminary evidence from a controlled trial in Haiti. Trop Med Int Health 2008, 13(1):56-67.

26. Hodgkin C, Molyneux DH, Abiose A, Philippon B, Reich MR, Remme JH, Thylefors B, Traore M, Grepin K: The future of onchocerciasis control in Africa. PLoS Negl Trop Dis 2007, 1(1):e74.

27. Hotez PJ: Forgotten people, forgotten diseases: the neglected tropical diseases and their impact on global health and development. Amer Soc Microbiol 2008, ASM Press, Washington USA, ISBN 978-1-55581-440-3.

28. Hotez PJ, Fenwick A, Savioli L, Molyneux DH: Rescuing the bottom billion through control of neglected tropical diseases. Lancet 2009, 373 (9674):1570-1575.

29. World Health O: Community-Directed Interventions for Major Health Problems in Africa: a Multi-Country Study: Final Report. Who, Special Programme for Research and Training in Tropical Diseases. Geneva: WHO; 2008.

doi:10.1186/2049-9957-3-24

Cite this article as: Das et al:: Community based interventions for the prevention and control of Non-Helmintic NTD. Infectious Diseases of Poverty 2014 3:24.

\section{Submit your next manuscript to BioMed Central and take full advantage of:}

- Convenient online submission

- Thorough peer review

- No space constraints or color figure charges

- Immediate publication on acceptance

- Inclusion in PubMed, CAS, Scopus and Google Scholar

- Research which is freely available for redistribution 